\title{
AMCP Partnership Forum: Enabling the Exchange of Clinical and Economic Information Pre-FDA Approval
}

\section{SUMMARY}

Current federal laws and FDA regulations have significantly restricted the sharing of clinical and health economic information on biopharmaceuticals that have yet to receive FDA approval. Over the past several years, organizations that make health care coverage decisions, including those that set copayments, premiums, and formulary placement, have expressed a need for receiving this information before approval, as long as appropriate safeguards exist to prevent this information from reaching unintended entities. Population health decision makers have indicated that waiting until FDA approval is often too late for the critical planning, budgeting, and forecasting associated with health benefit design, especially given the recent influx of high-cost medications and scrutiny for better evaluation and preparation. Recognizing that securities laws restrict the disclosure of nonpublic information and may need to be amended, permissible early dissemination would allow population health decision makers to incorporate clinical and economic information for pipeline drugs or expanded indications into financial forecasting for the following year's plan. Access to this information is needed 12-18 months before FDA approval when organizations are deciding on terms of coverage and budgetary assumptions for state health insurance rate filings, Medicare and Medicaid bids, contracts with health care purchasers, and other financial arrangements.

The need for exchange of clinical economic information before FDA approval was first introduced at a previous Academy of Managed Care (AMCP) forum in March 2016, which addressed section 114 of the Food and Drug Administration Modernization Act and the communication of such information after FDA approval. To address preapproval information specifically, AMCP convened a Partnership Forum on September 13-14, 2016. This forum included a diverse group of stakeholders representing managed care, the biopharmaceutical industry, providers, patients, health economists, academia, and others. The multistakeholder group represented the key professionals and entities affected by the federal laws and FDA regulations that restrict the sharing of preapproval information and the collective credibility necessary for proposing this new communication process.

Forum participants primarily focused on 6 items of discussion: (1) creating and defining new terms for how biopharmaceutical manufacturers may provide clinical and economic information 12-18 months before FDA approval; (2) defining the clinical and scientific standards that this information should meet; (3) determining which entities should have access to this information and the value to each; (4) the format and process by which this information should be disseminated; (5) developing definitions for existing terms referenced in current laws, regulations, or guidance documents that would need to be modernized to align with the identified new term; and (6) providing safeguards to prevent this information from reaching unintended entities.

Forum participants selected "preapproval information exchange" (PIE) as the correct term to describe this proposed new communication process and to be inclusive of data from pivotal phase III clinical trials, pharmacoeconomic data, and patient-reported outcomes, as well as other relevant items, including anticipated indications, place in therapy, and routes of administration. Stakeholders agreed that PIE should be truthful, nonmisleading, and include a broad range of information to meet the needs of population health decision makers and health care technology evolution. Recipients of PIE would be limited to population health decision makers who need this information for coverage decisions. The format and process for PIE disseminated should allow for a bidirectional exchange between manufacturers and population health decision makers but should not be proscribed in legislation. Furthermore, new legislative language may be beneficial, since PIE is a novel category of information. New legislation could provide a safe harbor and clarity that PIE does not violate preapproval promotion and the Federal Food, Drug, and Cosmetic Act and its regulations.

J Manag Care Spec Pharm. 2017;23(1):105-12

Copyright $\odot 2016$, Academy of Managed Care Pharmacy. All rights reserved.

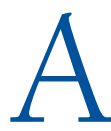
s the U.S. health care system evolves from a historical payment system based on quantity and process to a modernized system rewarding quality and improved patient outcomes, the need for timely communication between biopharmaceutical manufacturers and population health decision makers about emerging therapies is critical for the successful shift to a value-driven system. There are 3 main imperatives driving the need for communications before approval by the U.S. Food and Drug Administration (FDA). ${ }^{1,2}$

First, as a result of new laws such as the Affordable Care Act and state mandates, population health decision makers are required to evaluate their plan designs, formularies, and rates 12-18 months in advance to meet submission deadlines 6-9 months before the beginning of the intended plan year. With rates being filed over a year in advance, proper planning, budgeting, and forecasting are integral for population health decision makers to accurately account for the effect of new therapies that will enter the market. For example, for the 2016 coverage year, population health decision makers analyzed 2014 data in order to submit their 2016 rates by spring 2015 (Figure 1). The budget impact of new therapies that were approved by the FDA after spring 2015 could not be integrated into the 2016 rates. Accurate forecasting and rate setting is critical to ensure that patients have continued access to affordable coverage for their health care needs. Changes are necessary to FDA regulations to expressly permit biopharmaceutical manufacturers to proactively communicate with population health decision makers about emerging therapies before FDA approval so that more accurate forecasting and rate setting are supported, enabling affordable access for all patients to new therapies upon FDA approval.

Second, there is an increased focus on value-based payment models as evidenced by the Medicare Shared Savings Program and a range of initiatives launched and proposed by the Center for Medicare \& Medicaid Innovation. Successful implementation of value-based payment models requires understanding the overall value of a therapy, including how pharmacy spending can offset medical costs and vice versa. In addition, 

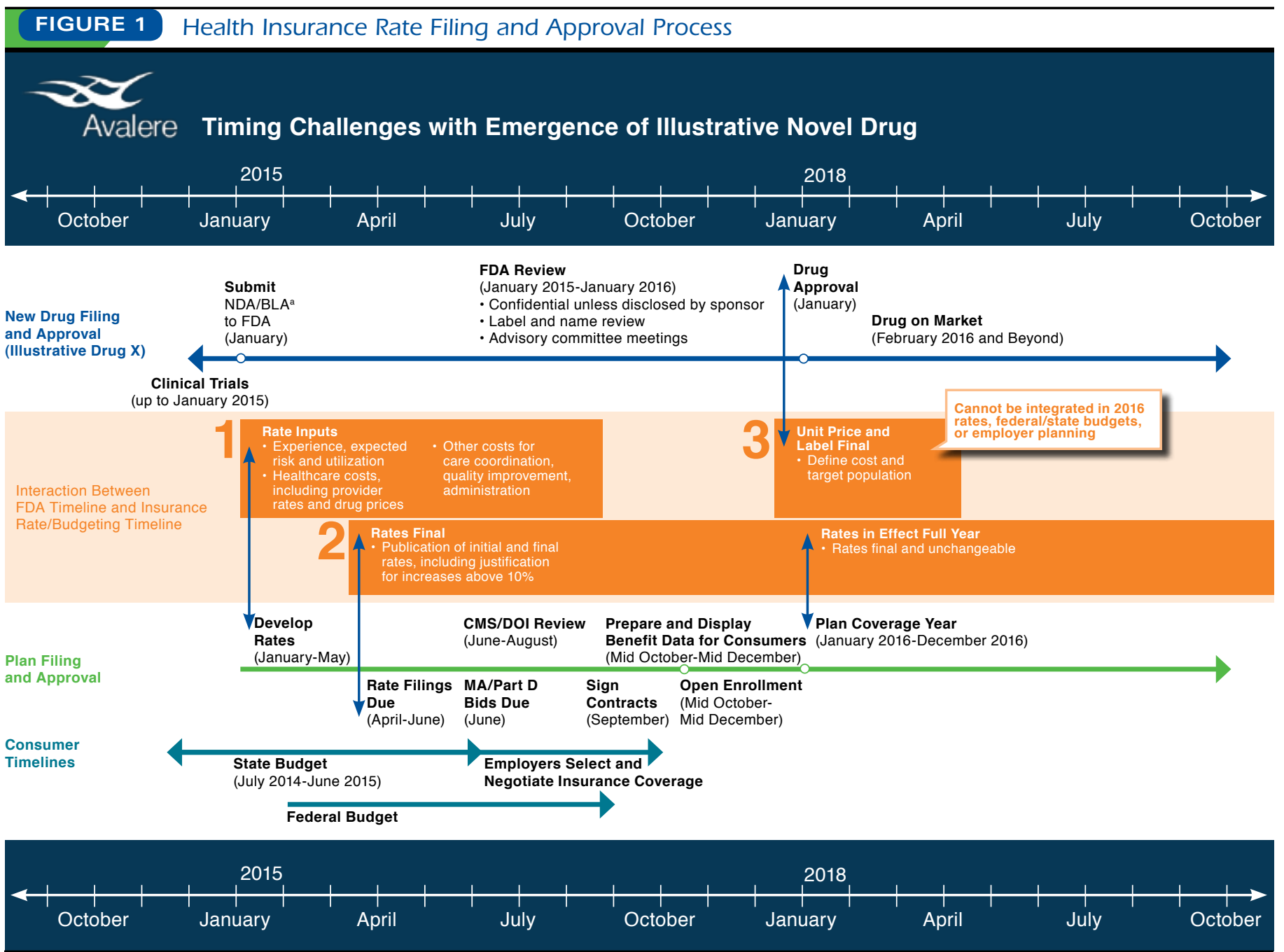

From Eli Lilly and Company and Anthem. Facilitating open communication about emerging therapies. January 29, 2016. Appendix. ${ }^{2}$ Reproduced with permission from Eli Lilly and Company.

${ }^{a}$ Median review time 1-2 years.

$B L A=$ Biologic License Application; CMS = Centers for Medicare \& Medicaid Services; DOI = Department of Insurance; FDA=U.S. Food and Drug Administration; $\mathrm{MA}=$ Medicare Advantage; NDA = New Drug Application.

it requires downstream planning for population health decision makers to change plan design, formularies, and necessary contracts in advance of submitting rates at least a year in advance of the intended coverage year as previously outlined. Therefore, to increase the use of value-based payment models, it is important for biopharmaceutical manufacturers and population health decision makers to be able to share information about emerging therapies before FDA approval in order to provide sufficient time to implement these models in a timely and effective manner upon FDA approval.

Finally, the Food and Drug Administration Safety and Innovation Act of 2012 (FDASIA) created an expedited approval pathway allowing the FDA to grant priority review if preliminary clinical trials indicate that a therapy may offer substantial treatment advantages over existing options for patients with serious or life-threatening diseases. ${ }^{3}$ Under the expedited approval pathway, therapies may be approved by the FDA before clinical trial data are published and made publicly available, thereby making it very difficult for population health decision makers to determine whether a therapy is appropriate for a patient if they receive a coverage request before publication of the data. Guidelines and peer-reviewed compendia sources are even further delayed in providing population health decision makers with reputable reference material for making sound clinical judgements when published clinical data are not available. In these situations, enabling preapproval information 


\begin{tabular}{|c|c|c|}
\hline & $\begin{array}{l}\text { FDA Guidance } \\
\text { Regarding Clari } \\
\text { Dissemination o } \\
\text { Information }\end{array}$ & $\begin{array}{l}\text { and Other Initiatives } \\
\text { fication of the } \\
\text { f Off-Label Drug }\end{array}$ \\
\hline Year & Topic & Title (if applicable) \\
\hline$\overline{1997}$ & $\begin{array}{l}\text { Guidance on the scientific } \\
\text { exchange of original trial results } \\
\text { and off-label information }\end{array}$ & $\begin{array}{l}\text { Industry-Supported Scientific } \\
\text { and Educational Activities }{ }^{4}\end{array}$ \\
\hline 2009 & $\begin{array}{l}\text { Guidance on the distribution } \\
\text { of peer-reviewed scientific and } \\
\text { medical publications regard- } \\
\text { ing unapproved new uses of } \\
\text { approved drugs and approved/ } \\
\text { cleared medical devices }\end{array}$ & $\begin{array}{l}\text { Good Reprint Practices for } \\
\text { the Distribution of Medical } \\
\text { Journal Articles and Medical or } \\
\text { Scientific Reference Publications } \\
\text { on Unapproved New Uses of } \\
\text { Approved Drugs and Approved } \\
\text { or Cleared Medical Devices }\end{array}$ \\
\hline 2011 & $\begin{array}{l}\text { Guidance reflecting responses } \\
\text { to unsolicited requests }\end{array}$ & $\begin{array}{l}\text { Responding to Unsolicited } \\
\text { Requests for Off-Label } \\
\text { Information About Prescription } \\
\text { Drugs and Medical Devices }\end{array}$ \\
\hline 2011 & $\begin{array}{l}\text { MIWG petition regarding } \\
\text { clarification on off-label } \\
\text { communication }\end{array}$ & $\begin{array}{l}\text { Citizen Petition, } \\
\text { FDA-2011-P-50129 }\end{array}$ \\
\hline 2013 & $\begin{array}{l}\text { MIWG petition requesting a } \\
\text { constitutional response to } 2011 \\
\text { petition (above) }\end{array}$ & $\begin{array}{l}\text { Citizen Petition, } \\
\text { FDA-2013-P-107910 }\end{array}$ \\
\hline 2014 & Update to 2009 guidance & $\begin{array}{l}\text { Distributing Scientific and } \\
\text { Medical Publications on } \\
\text { Unapproved New Uses- } \\
\text { Recommended Practices }^{7}\end{array}$ \\
\hline 2015 & $\begin{array}{l}\text { Declaration that detailed the } \\
\text { FDA's initiatives to accom- } \\
\text { modate policies to foster stake- } \\
\text { holder interests in off-label } \\
\text { communication }\end{array}$ & $\begin{array}{l}\text { Declaration by Janet } \\
\text { Woodcock }^{11}\end{array}$ \\
\hline
\end{tabular}

exchange (PIE) is critical to ensuring that population health decision makers are aware of the information available to date on emerging therapies granted breakthrough designation by the FDA so that they are prepared to make coverage decisions for patients immediately upon FDA approval.

\section{Restricting Information Dissemination}

Current federal laws and FDA regulations have significantly restricted communications between biopharmaceutical manufacturers and population health decision makers for emerging therapies before FDA approval, despite clear recognition that budgeting and forecasting by payers is critical to ensure that patients have access to new treatments as soon as possible following market approval. Over the past 3-4 decades, the FDA has disseminated various policy documents addressing this issue. ${ }^{4-7}$ While safe harbors for off-label communication already exist, the interpretation is unclear, and enforcement involves various entities with differing approaches (i.e., Health and Human Services Office of the Inspector General, Federal Trade Commission, Department of Justice, and state governments). ${ }^{8}$
FDA regulations ensure access to safe and effective medications, while other agencies must ensure prevention of fraud, waste, and abuse, and marketplace competition. Uncertainty regarding safe harbors and the fear of enforcement has limited the dissemination of preapproval information by manufacturers, despite population health decision makers and others expressing a strong need for this information much earlier in the drug development process. There is a definitive need to refine and clarify laws governing activities under the purview of the FDA to help diminish concerns about the possibility of legal action by other agencies. More recently, the FDA has drafted guidance to take steps to support solutions to distinct, yet related, communication challenges; granted petitions to elucidate on this topic; and announced a public hearing to review policies and clarify standards for off-label communication. ${ }^{4-11}$ This topic has also been heavily discussed outside of the FDA, including at AMCP's FDAMA Section 114 forum, 21st Century Cures proposals for reform of Section 114, Biotechnology Innovation Organization and Pharmaceutical Research and Manufacturers of America's principles on responsible sharing for truthful and non-misleading information, among others (Table 1).12-14

Given these circumstances and others discussed in the following proceedings, further recommendations, guidance, and legislation are needed to provide clarity on the dissemination of information before FDA approval.

\section{Forum Purpose and Discussion Points}

To address the long-debated issue of proactive dissemination of clinical and health economic information on products before FDA approval, the Academy of Managed Care Pharmacy (AMCP) held a Partnership Forum on September 13-14, 2016, in Tysons Corner, Virginia, with a diverse group of health care stakeholders to provide recommendations for Congress and the FDA. The purpose of this forum was to discuss the following 6 items:

1. The term that would be used to describe the ability of biopharmaceutical manufacturers to proactively share clinical and economic information about medications in the pipeline with payers and other entities before FDA approval.

2. The standards that clinical and economic information should meet before FDA approval.

3. Stakeholders who should have access to clinical and economic information before FDA approval and the value of this information to each of these entities or individuals.

4. The preferred format and process by which eligible entities would like to receive clinical and economic information from biopharmaceutical manufacturers before FDA approval.

5. The definitions for existing terms referenced in current laws, regulations, or guidance documents (i.e., labeling, misbranded, or intended use) that would need to be modernized to align with the identified new term for the exchange of clinical and economic information before FDA approval. 
TABLE 2 Summary of the AMCP FDAMA 114 Partnership Forum ${ }^{12}$

\begin{tabular}{|c|c|c|}
\hline Objective & \multicolumn{2}{|c|}{$\begin{array}{l}\text { AMCP convened a Partnership Forum for stakeholders to discuss clarification and possible expansion of FDAMA Section } 114 \text { to } \\
\text { obtain consensus recommendations on how information related to this statute should be disseminated. }\end{array}$} \\
\hline Key stakeholders & \multicolumn{2}{|c|}{$\begin{array}{l}\text { Pharmaceutical industry, managed care industry, health care providers, pharmacoeconomic experts, health policy experts, and } \\
\text { patient advocates }\end{array}$} \\
\hline \multicolumn{3}{|c|}{ Recommendations: Terms, Definitions, and Key Points } \\
\hline Term & Definition & Key Points \\
\hline $\begin{array}{l}\text { Competent and } \\
\text { reliable scientific } \\
\text { evidence }\end{array}$ & $\begin{array}{l}\text { "Truthful and non-misleading tests, analyses, research, studies, } \\
\text { models, or other evidence. Such evidence would be based } \\
\text { on the expertise of professionals in the relevant area and be } \\
\text { derived using methods that are transparent, disclosed, repro- } \\
\text { ducible, accurate, and valid." }\end{array}$ & Models would be left behind with reproducible methods. \\
\hline $\begin{array}{l}\text { Formulary or other } \\
\text { similar entity }\end{array}$ & $\begin{array}{l}\text { "Health care decision makers beyond health plan formulary } \\
\text { committees, including organizations, or individuals in their role } \\
\text { in an organization, who make health care decisions for patient } \\
\text { populations and organizations that evaluate HCEI or develop } \\
\text { value frameworks and compendia, including individuals } \\
\text { in such organizations." }\end{array}$ & $\begin{array}{l}\text { - "Other entity" needs to be flexible as the health care industry } \\
\text { evolves over time. } \\
\text { - The role of the individual needs to be a key consideration. } \\
\text { - Inclusion of patient advisory groups was debated, since some } \\
\text { of these groups are sophisticated and have the ability to inter- } \\
\text { pret this information, but not all do, so proper protections } \\
\text { need to be considered. }\end{array}$ \\
\hline $\begin{array}{l}\text { Health care economic } \\
\text { information }\end{array}$ & $\begin{array}{l}\text { "Any analysis that identifies, measures, or compares the eco- } \\
\text { nomic, clinical, or quality of life consequences for any treat- } \\
\text { ment. This includes the costs and resource utilization of a drug } \\
\text { or health technology relative to another drug, health technology, } \\
\text { or no intervention." }\end{array}$ & $\begin{array}{l}\text { Includes noneconomic information as well, since clinical and } \\
\text { quality life endpoints are a part of economic evaluation. }\end{array}$ \\
\hline
\end{tabular}

AMCP=Academy of Managed Care Pharmacy; FDAMA=Food and Drug Administration Modernization Act; HCEI=health care and economic information.

6. The public health protections that should be considered to prevent the dissemination of clinical and economic information to unintended entities before FDA approval.

AMCP previously held a Partnership Forum in March 2016 to address communications of health care economic information (HCEI) after FDA approval. More specifically, the March forum discussed the clarification and possible expansion of Section 114 of the Food and Drug Administration Modernization Act (FDAMA) to obtain consensus recommendations on how information related to this statute should be disseminated. ${ }^{12}$ While the recommendations from the March forum (Table 2) were focused on HCEI dissemination after FDA approval, a key recommendation was that further discussion was warranted to create recommendations for information exchange before FDA approval.

Stakeholders participating in the September Partnership Forum on preapproval communications were separated into 3 groups. Throughout the forum, each group, which was composed of representatives from the biopharmaceutical industry, payers, provider organizations, academia, health economists, and patient advocacy groups, among others, began its discussion with the question of whether the recommendations from the March forum on post-FDA approval communications were applicable to pre-FDA approval communications or whether the latter required adjustments given the differences in purpose and use before versus after FDA approval. The following recommendations and discussion points are reported to reflect where there was agreement, and where further discussion is warranted.

\section{Terminology to Describe the Sharing of Preapproval} Clinical and Economic Information

When considering the terminology that should be used to describe the ability of biopharmaceutical manufacturers to proactively share clinical and economic information about medications in the pipeline with payers and other entities before FDA approval, debate among the 3 groups focused on 3 areas: (1) the term "preapproval," (2) whether the information to be communicated should be information or evidence, and (3) whether the method of conversation should be deemed an exchange or information sharing.

\section{Preapproval}

The groups discussed the need for a term that is narrow enough to be included in legislation or adopted in guidance. Whether to include "preapproval" in this term was debated. Stakeholders reached consensus that the final recommended term should differentiate what type of information is to be shared. Including the word "preapproval" in any such term would highlight that the term refers to information disclosed for forecasting, planning, and budgeting before FDA approval. A key point of discussion was when pricing information would be available for medicines initially entering the market. Some stakeholders noted that pricing may only be known shortly, if not immediately, before product launch, while other stakeholders expressed an interest in receiving pricing information, or at least a range of possible prices, as early as possible. Stakeholders recognized, however, that manufacturers must 
comply with securities and trade secrets laws that restrict the dissemination of material nonpublic information, which could include pricing, as well as certain clinical trial data.

\section{Information Versus Evidence}

The terms "information" and "evidence" were used to describe the clinical and economic data to be communicated. Although the term "scientific information" was proposed, stakeholders agreed that this term may be misinterpreted as being limited to research studies subject to scientific rigor, when instead, the proposed term should be inclusive of additional purposes (e.g., identifying potential patient-populations, distribution requirements, and budgeting). Some stakeholders indicated that as biopharmaceuticals move through the early phases of development, information builds over time and eventually leads to a body of evidence in the later phases of development and throughout the product life cycle. Furthermore, the term "information" was deemed appropriate by some because "evidence" may be viewed as only the types of data that involve a statistical comparison and may limit the use of models and valuable cost analyses. Stakeholders expressed that models cannot be classified as evidence, since they are simply tools to develop estimations, and there was a strong concern among many stakeholders that deeming a model as evidence would lead to misinterpretation as to what such models can and cannot demonstrate and depict from a level of certainty. Those who supported use of the term "evidence" stated that "information" is a broader and more encompassing term that may not have as much weight in the scientific community. The concept of information versus evidence is discussed in more detail throughout this proceedings document.

\section{Exchange Versus Information Sharing}

The third area of discussion focused on the terms "exchange" versus "information sharing." Supporters of the term "exchange" felt that the use of this term would signify bidirectional conversations between decision makers and manufacturers and reinforce an ongoing dialogue between the 2 parties. Proponents of the term "information sharing" thought that the term "exchange" would be confused with scientific exchange, which has traditionally been interpreted to be applicable to investigational new drugs under 21 CFR 312.7(a) and therefore expressed hesitance in using this term.

After thorough discussion, stakeholders agreed on the term "preapproval information exchange" (PIE), which referred to the proactive sharing of clinical and economic information by manufacturers to decision makers (entities are discussed later in the proceedings) at least 12-18 months before FDA approval and the ongoing discussions between the 2 sharing entities as information evolves into evidence throughout drug development. Furthermore, stakeholders agreed that this preapproval communication only applies to those biopharmaceutical manufacturers who intend to file for a new indication (new molecules and new indications), thereby limiting the risk for off-label promotion. Stakeholders agreed that the intent of a biopharmaceutical manufacturer to file would need to be justified by submission of an Investigational New Drug (IND) application, New Drug Application (NDA), Supplemental New Drug Application (sNDA), or other similar steps.

\section{Standards for Preapproval Information}

Discussion on the question "What standards should clinical and economic information shared prior to FDA approval meet?" began with the definition of "competent and reliable scientific evidence" as developed in the FDAMA 114 forum (Table 2) and how to differentiate the preapproval setting from the postapproval setting. Overall, stakeholders agreed that the standards for this information should be based on the FDAMA 114 forum definition, with a few proposed exceptions:

- "Information" should be either added to the definition or should replace "evidence."

- A minimum set of standards should be set for this information, but as a biopharmaceutical product approaches approval, the information would become stronger and evolve into evidence.

- It was emphasized that because the information about a product could change and augment over time, any disclosure of information for PIE purposes needed to include transparency regarding the methods and results (all of which would need to be done in a truthful and non-misleading manner) with appropriate disclosures of uncertainty and limitations inherent in such information, and methods would need to be reproducible-not the results).

Some stakeholders expressed that all-inclusive information sharing, with ultimately no restrictions, may allow too much lenience, while being too specific may inhibit manufacturers from sharing important information with population health decision makers that would be of value to their decisions and ultimately be important for planning and forecasting purposes. As mentioned in the previous section, limiting the standards to "evidence" may cause legal concern and be interpreted as requiring a level of research or replicability for all information disclosed, which might be unattainable at certain stages of the product's development, whereas the intent is to be able to include additional items such as anticipated indications, place in therapy, routes of administration, distribution channels, and potential budget impact.

\section{Entities and Individuals Who}

\section{Should Receive Preapproval Information}

During the FDAMA 114 forum, it was decided that entities who should receive HCEI after FDA approval would be "health care decision makers beyond health plan formulary 
committees, including organizations, or individuals in their role in an organization, who make health care decisions for patient populations and organizations that evaluate HCEI or develop value frameworks and compendia, including individuals in such organizations" (Table 2). Stakeholders were asked to consider these same entities for preapproval purposes, in addition to pharmacy and therapeutic committees, managed care pharmacy, health care providers, accountable care organizations (ACOs), integrated delivery networks, patient advocacy groups (PAG), organizations that develop value frameworks (e.g., American Society of Clinical Oncology and National Comprehensive Cancer Network), organizations that develop clinical practice guidelines (e.g., American College of Cardiology and American Diabetes Association), research societies (e.g., International Society for Pharmacoeconomics and Outcomes Research), actuaries, contract specialists, and others.

All stakeholders agreed that population health decision makers such as managed care organizations and pharmacy benefit managers would be eligible to receive preapproval information. In addition, certain integrated delivery networks (IDNs) and ACOs that bear financial risk for biopharmaceuticals would also be eligible to receive preapproval information. These population health decision makers were included because entities and individuals within these organizations need to receive this information in advance of FDA approval for budgeting, forecasting, and coverage decision purposes.

Forum stakeholders also considered whether other entities that are "influencers," such as groups that develop value frameworks and clinical practice guidelines should be included in PIE. Some stakeholders thought that clinical practice guidelines developers would need to know this information, since the evolution of guidelines is a lengthy process, and it would be beneficial to know this information for the next guideline update. A limited number of stakeholders thought that some benefit exists in expanding this information sharing to PAGs, since the FDA is moving toward more patient-focused drug development. However, the majority of stakeholders strongly argued that the need for HCEI is for entities that have accountability for forecasting costs to ensure patient access and coverage, which is not the case for influencers or PAGs. While preapproval information sharing with influencers and PAGs was considered, there was consensus that the pre-FDA approval information most valuable to influencers and PAGs was clinical in nature, not preliminary economic or financial data. Furthermore, entities such as influencers or PAGs could receive this information through the usual channel of unsolicited requests. Therefore, the majority of stakeholders agreed that only entities who manage a population's health should receive preapproval information.

\section{Preferred Format and Process for Receiving Preapproval Information}

After reviewing the recommendations set forth at the FDAMA 114 forum, stakeholders were asked the question "What is the preferred format and process by which eligible entities would like to receive clinical and economic information prior to FDA approval from biopharmaceutical manufacturers?". Overall, stakeholder consensus supported the creation of a flexible means of providing this information that allows for a bidirectional exchange between manufacturers and population health decision makers and that a specific format or process should not be prescribed in legislation. Furthermore, AMCP was identified as a potential driver and leader in this space, given that AMCP has an established process for communication of information about biopharmaceutical products to inform decisions made by formulary committees. This process is currently restricted to unsolicited requests but could be adapted for PIE. Conversely, a few key points were debated:

1. Central repository versus repositories for each manufacturer. Some stakeholders thought that having multiple repositories (each for a different biopharmaceutical manufacturer) would simplify the risk of unintended users gaining access to preapproval information. Others stated that having the ability to compare medications and technologies in a central repository during a single log-in would allow for a more simplified, effective process. The central repository would allow for alerts once information is updated-decision makers could choose to opt-in and the frequency of the alerts they would like to receive (e.g., once a month or once a week). Later in the discussion, stakeholders noted that AMCP already has a central repository system in place for dossier submissions and viewing; therefore, this same system could be adapted as an option for communicating information in the preapproval setting.

2. Standardized format versus flexible format. An AMCP dossierlight format was initially suggested by many stakeholders, while others were concerned that not all end users, such as IDNs and ACOs, would be as familiar with this format; therefore, the format would need to be adaptable and flexible to suit the needs of organizations or entities. Furthermore, technology is rapidly evolving and developing, so a format developed today may not be useful tomorrow. Others disagreed, stating that a standardized format with the ability to locate the same information in the same location between 2 products would allow for a more simplified, consistent process.

3. Communication and notification. Communications via a repository would include notifications to decision makers once information was updated, options for manufacturers to share models and slide-decks, and one-on-one conversations between manufacturers and decision makers. More importantly, manufacturers and decision makers would have the option to choose the type and frequency of 
engagement, depending on their individual needs, and whether to use a central repository or another process for exchanging this information.

Stakeholders ultimately agreed that the forum discussion is a starting point for the consideration of format options and that a specific format or process should not be prescribed in legislation but should be developed collaboratively between the manufacturers and population health decision makers who would be exchanging this information. The group agreed that given AMCP's history of providing this type of information, it is in a good position to serve as a leader and developer for providing information under PIE.

\section{Definitions for Existing Terms in Current}

\section{Laws, Regulations, or Guidance Documents}

Given the existing terms included in current laws, regulations, and guidance documents, stakeholders were asked the question "How should the definitions for existent terms, referenced in current laws, regulations, or guidance documents (such as labeling, misbranded, or intended use) be modernized to align with the identified new term for the exchange of clinical and economic information before FDA approval?". Stakeholders quickly reached a consensus that PIE would need to have its own safe harbor, in a manner consistent with existing law.

\section{Public Health Protections to Prevent the} Dissemination of Preapproval Information

Stakeholders considered the public health protections required to prevent the dissemination of preapproval information and agreed that it should function similarly to the system in place for HCEI under FDAMA Section 114. The stakeholders agreed that certain public health protections are already in place through other legislation, so there may not be a need to create further protections beyond those already enacted.

\section{Conclusions}

$\overline{\text { Currently, the sharing of clinical and health care economic }}$ information on new products and indications before FDA approval is significantly restricted by federal laws and FDA regulations regarding product promotion. Population health decision makers have expressed a need for receiving this information at least 12-18 months before FDA approval to properly plan, budget, forecast, and care for the populations they serve, as long as safeguards are in place to prevent preapproval information from reaching unintended entities. The recommendation from this Partnership Forum is for Congress to establish a safe harbor for preapproval information exchange between biopharmaceutical manufactures and population health decision makers to encourage better decision making, without interfering with innovation in the biopharmaceutical and health technology industry.

\section{Forum Participants}

ALEXIS AHLSTROM, MPH, Director, GlaxoSmithKline; ANDREW BEHM, PharmD, CGP, Vice President, Express Scripts; CHRISTOPHER MICHAEL BLANCHETTE, PhD, MBA, Vice President, Evidence Strategy \& Generation, Precision Health Economics, Associate Professor, Public Health Sciences, University of North Carolina at Charlotte; ELIZABETH L. BRUSIG, PharmD, MBA, Clinical Pharmacy Specialist, Optima Health Plan; SUSMITA CHAVALA, PharmD, MHA, Senior Principle, Clinical Policy, Prime Therapeutics; GREGORY DANIEL, PhD, MPH, RPh, Deputy Director, Duke-Margolis Center for Health Policy; AMY DUHIG, PhD, Senior Director, Outcomes Research, Xcenda; PAUL EITING, MPP, Senior Manager, Value-Based Policy, Blue Cross Blue Shield Association; ELIZABETH ENGELHARDT, RN, BSN, Head of Specialty Strategy \& Clinical Management, Aetna; JEFFREY K. FRANCER, JD, MPP, Vice President and Senior Counsel, Pharmaceutical Research and Manufacturers of America; JENNIFER GRAFF, PharmD, Vice President, Comparative Effectiveness Research, National Pharmaceutical Council; JOEL W. HAY, PhD, MS, MPhil, Professor, University of Southern California; DOROTHY HOFFMAN, MPP, Director, Global Public Policy/Head, U.S. Health Policy, Eli Lilly and Company; KAT WOLF KHACHATOURIAN, PharmD, Vice President, Pharmacy Services \& Strategy, Qualchoice Health Plan Services; CRYSTAL L. KUNTZ, MPA, Vice President, Policy and Regulatory Affairs, America's Health Insurance Plans (AHIP); JEFF LEE, PharmD, FCCP, Associate Professor, Pharmacy Practice, Lipscomb University College of Pharmacy; ERIN LOPATA, PharmD, Manager of Clinical Pharmacy, UPMC Health Plan; JAMES K. MARTTILA, PharmD, MBA, Director, Pharmaceutical Contracting and Formulary Management, Mayo Clinic; JOAN S. MCCLURE, MS, Senior Vice President of Clinical Information and Publications, National Comprehensive Cancer Network; NEWELL MCELWEE, PharmD, MSPH, Associate Vice President, Center for Observational and Real World Evidence, Merck; COREY PELLETIER, PhD, Director, US Health Economics \& Outcomes Research, Celgene; ELEANOR M. PERFETTO, PhD, MS, Professor, Pharmaceutical Health Services Research, University of Maryland School of Pharmacy, Senior Vice President, Strategic Initiatives, National Health Council; MICHAEL RYAN, PharmD, Senior Vice President, Value Access \& Payment, Bristol-Myers Squibb; SHEILA M. THOMAS, PharmD, Senior Director, Evidence Based Medicine, Sanofi; ROBIN S. TURPIN, PhD, Lead Director, HEOR, Takeda Pharmaceuticals, USA; ANTHONY WANG, PhD, MPH, Senior Manager HEOR, AbbVie; MELEA WARD, PhD, PharmD, BCPS, Director, Outcomes and Evidence, Pfizer Oncology; JAMES WEATHERALL, BBA, MA, PhD, Director, Health Economics \& Outcomes Research, Novo Nordisk; SUSAN C. WINCKLER, RPh, Esq., Chief Risk Management Officer, Leavitt Partners; KRISTINA YU-ISENBERG, PhD, MPH, RPh, Vice President and Head, Evidence Generation and Analytics, Intarcia Therapeutics; and LORI ZABLOWSALLES, Esq., Executive Director, Executive Counsel, Boehringer Ingelheim Pharmaceuticals.

AMCP STAFF: SUSAN A. CANTRELL, RPh, CAE, Chief Executive Officer; MARY JO CARDEN, RPh, JD, Vice President of Government \& Pharmacy Affairs; CHARLIE DRAGOVICH, BSPharm, Senior Director of Business Development \& Strategic Alliances; ASHLEY LANHAM, PharmD, MBA, Manager of Student Development $\&$ New Practitioner Programs; and SOUMI SAHA, PharmD, JD, Assistant Director of Pharmacy \& Regulatory Affairs.

CORRESPONDENCE: Soumi Saha, PharmD, JD, Assistant Director of Pharmacy \& Regulatory Affairs, Academy of Managed Care Pharmacy, 675 N. Washington St., Ste. 220, Alexandria, VA 22314.

E-mail:ssaha@amcp.org. 


\section{DISCLOSURES}

The AMCP Partnership Forum on Enabling the Exchange of Clinical and Economic Data Pre-FDA Approval and the development of this proceedings document were supported by AbbVie, Boehringer Ingelheim Pharmaceuticals, Bristol-Myers Squibb, Celgene, Intarcia Therapeutics, Eli Lilly and Company, GlaxoSmithKline, Merck, National Pharmaceutical Council, Novo Nordisk, Pfizer, Pharmaceutical Research and Manufacturers of America, Precision for Value, Sanofi, Takeda Pharmaceuticals, U.S.A., and Xcenda. All sponsors participated in the forum and in revising and approving the manuscript.

\section{ACKNOWLEDGMENTS}

The AMCP Partnership Forum on Enabling the Exchange of Clinical and Economic Data Pre-FDA Approval was moderated by Susan Denzter, President and CEO, The Network for Excellence in Health Innovation (NEHI). The proceedings document was written by Emily Zacherle, MS, Evidence Strategy, Generation and Communication, Precision Health Economics.

\section{REFERENCES}

1. Nussbaum S, Ricks D. Discovering new medcines and new ways to pay for them. Health Affairs Blog. January 29, 2016. Available at: http://healthaffairs. org/blog/2016/01/29/discovering-new-medicines-and-new-ways-to-pay-forthem/. Accessed December 12, 2016.

2. Eli Lilly and Company and Anthem. Facilitating open communication about emerging therapies. January 29, 2016. [Pages 6-9] Available at: http://thinkanthem.com/sites/default/files/ProjectIndy_FDACommunication _1.29.15.pdf. Accessed December 12, 2016.

3. Food and Drug Administration Safety and Innovation Act (FDASIA) §902, Pub. L. 112-144, 126 Stat. 993 (2012). Available at: https://www.congress. gov/112/plaws/publ144/PLAW-112publ144.pdf. Accessed December 12, 2016.

4. U.S. Food and Drug Administration. Guidance for Industry: IndustrySupported Scientific and Educational Activities, 62 Fed. Reg. 64,093. December 3, 1997. Available at: http://www.fda.gov/downloads/Regulatory Information/Guidances/UCM125602.pdf. Accessed December 12, 2016.

5. U.S. Food and Drug Administration. Good reprint practices for the distribution of medical journal articles and medical or scientific reference publications on unapproved new uses of approved drugs and approved or cleared medical devices. January 2009. Available at: http://www.fda.gov/RegulatoryInformation/ Guidances/ucm125126.htm. Accessed December 12, 2016.
6. U.S. Food and Drug Administration. Guidance for industry: responding to unsolicited requests for off-label information about prescription drugs and medical devices. Draft guidance. December 2011. Available at: http:// www.fda.gov/downloads/drugs/guidancecomplianceregulatoryinformation/ guidances/ucm285145.pdf. Accessed December 12, 2016.

7. U.S. Food and Drug Administration. Guidance for industry: distributing scientific and medical publications on unapproved new uses-recommended practices. Revised draft guidance. February 2014. Available at: http://www. fda.gov/downloads/drugs/guidancecomplianceregulatoryinformation/guidances/ucm387652.pdf. Accessed December 12, 2016.

8. Daniel GW, Romine MH, Allen J, et al. Policy options for off-label communication: supporting better information, better evidence, and better care. Duke-Margolis Center for Health Policy. February 2016. Available at: https:// www.pharmamedtechbi.com/ /media/Supporting\%20Documents/The\%20 Gray\%20Sheet/42/8/160218_OffLabel.pdf. Accessed December 12, 2016.

9. Medical Information Working Group. Citizen Petition to U.S. Food and Drug Administration. FDA-2011-P-0512. July 2011. Available at: https:// www.regulations.gov/document?D=FDA-2011-P-0512-0001. Accessed December 12, 2016.

10. Medical Information Working Group. Citizen Petition to U.S. Food and Drug Administration. FDA-2013-P-1079. September 3, 2013. Available at: http://www.cohealthcom.org/wp-content/uploads/2013/09/citizen-petition. pdf. Accessed December 12, 2016.

11. Declaration of Janet Woodcock, M.D. at 25, Amarin, 119 F. Supp. 3d 196 (SDNY 2015) (No. 15-CV-3588).

12. AMCP Partnership Forum: FDAMA Section 114-Improving the Exchange of Health Care Economic Data [proceedings]. J Manag Care Spec Pharm. 2016;22(7):826-31. Available at: http://www.jmcp.org/doi/10.18553/ jmcp. 2016.22.7.826.

13. Pharmaceutical Research and Manufacturers of America. Principles on responsible sharing of truthful and non-misleading information about medicines with health care professional and payers. Available at: http://phrma. org/sites/default/files/pdf/information-sharing-with-hcps-principles-report. pdf. Accessed December 12, 2016

14. 21st Century Cures Act. H.R. 6. 114th Congress (2015-2016). Available at: https://www.congress.gov/bill/114th-congress/house-bill/6/text. Accessed December 12, 2016. 